Accepted manuscript of article accepted for publication in British Journal of Learning Disabilities.

\title{
Health monitoring of young children with Down syndrome: A parent-report study
}

Silvana E Mengoni ${ }^{\mathrm{a}}$ and Sandra Redman ${ }^{\mathrm{b}}$

a Centre for Health Services and Clinical Research, Department of Psychology and Sports Sciences, University of Hertfordshire, Hatfield, UK.

b Talking Downs, Stevenage, UK.

Running title: Health monitoring in Down syndrome

Corresponding author

Silvana Mengoni

s.mengoni@herts.ac.uk 01707284494

Centre for Health Services and Clinical Research, Department of Psychology and Sports Sciences, University of Hertfordshire, Hatfield, UK.

Data availability statement

The data that support the findings of this study are available from the corresponding author upon reasonable request.

Acknowledgements

The authors would like to thank the parents who took in the study and shared their experiences. The support of Downright Excellent and Barnet Council in facilitating recruitment is gratefully acknowledged. The authors also thank Rachael Mellor for her assistance with literature searching, data collection and data entry, and David Wellsted for his helpful comments on earlier drafts of this paper. This study was funded by a University of Hertfordshire Early Career Researcher award to SM. 
Accepted manuscript of article accepted for publication in British Journal of Learning Disabilities.

\title{
Health monitoring of young children with Down syndrome: A parent-report study
}

\section{Accessible summary}

- Young children with Down syndrome often have serious health conditions, such as heart or thyroid problems.

- It is important that health professionals follow guidelines to make sure that these health conditions are diagnosed and treated.

- We asked parents of children with Down syndrome aged 0-5 years whether their child had received healthcare as set out in the guidelines.

- Parents reported that guidelines were mostly followed at birth and for diagnosed health conditions. Guidelines were less likely to be followed after birth and for checking for undiagnosed health conditions.

\section{Keywords}

Down syndrome; Learning (intellectual) disabilities; Care management; Health and social care policy and practice

\begin{abstract}
Background

Children with Down syndrome have an increased risk of serious health conditions, particularly in early childhood. Published guidelines promote the identification and monitoring of health issues and adherence could reduce health inequalities, yet there is limited research about the extent to which health monitoring occurs as recommended. This study aimed to investigate the health monitoring of children with Down syndrome aged 0-5 years in the UK.
\end{abstract}

\section{Materials and Methods}

Twenty-four parents of children with Down syndrome with a mean age of 32 months (10-65 months) participated. They completed a questionnaire about their child's healthcare usage, diagnoses of health conditions and whether health checks had been completed at birth and since birth. The 
Accepted manuscript of article accepted for publication in British Journal of Learning Disabilities.

results of the questionnaires were charted, and compared to the schedule of checks produced by the Down Syndrome Medical Interest Group UK.

Results

Children with Down syndrome had high usage of health services and reported significant health issues. There was high adherence to published guidelines for the majority of health checks at birth, although $38 \%$ of children had not received all recommended checks. Not all health domains had been monitored since birth for all children, particularly breathing and blood (excluding thyroid). With the potential exception of sleep apnea, diagnosed conditions appeared to be monitored.

\section{Conclusions}

This study suggests that health monitoring after birth and screening for non-diagnosed health conditions is variable for children with Down syndrome. Further research should examine convergence of these findings with medical records and clinicians' experiences across the UK. 
Accepted manuscript of article accepted for publication in British Journal of Learning Disabilities.

\section{Introduction}

Children with intellectual disabilities often experience health inequalities, which can continue into adulthood and reduce quality of life (Allerton, Welch, \& Emerson, 2011). Down syndrome is associated with an increased risk of a number of health conditions, many of which begin in early childhood or are present at birth and result in unmet health needs and health inequalities (Bull \& The Committee on Genetics, 2011; Cleves et al., 2007; McGrath, Stransky, Cooley, \& Moeschler, 2011; Schieve, Boulet, Boyle, Rasmussen, \& Schendel, 2009; Thomas et al., 2011).

In England and Wales, 700-800 babies are born with Down syndrome each year (Wu \& Morris, 2013). Compared to newborn babies without Down syndrome, newborn babies with Down syndrome are more likely to have heart, nervous system, ear, eye, orofacial and gastrointestinal issues (Cleves et al., 2007). Due to an increased likelihood of experiencing serious health conditions, young children with Down syndrome have increased needs for health services compared to children in the general population. Hospitalisation rates are higher than for the general population of children (Thomas et al., 2011), particularly in the first year of life (Dawson et al., 2014), and for children with congenital heart defects (Frid, Annerén, Rasmussen, Sundelin, \& Drott, 2002). Compared to the general population, children with Down syndrome were more likely to have seen a medical specialist in the previous 12 months and they were more likely than children with an intellectual disability other than Down syndrome to have visited the emergency department multiple times (Schieve et al., 2009). Compared to other children with special health care needs, children with Down syndrome are less likely to receive family-centred care, and are more likely to have unmet care needs and negative impacts on parental finances and employment (McGrath et al., 2011).

The evidence base about healthcare costs in Down syndrome is limited but consistently shows high costs, particularly in the early years of life (Dawson et al., 2014; Geelhoed, Bebbington, Bower, Deshpande, \& Leonard, 2011). Key contributors to the cost of care for children with Down syndrome include hospitalisation, therapy, respite care and prescription drugs (Boulet, Molinari, Grosse, Honein, \& Correa-Villaseñor, 2008; Geelhoed et al., 2011). Younger children and children with congenital health problems, particularly heart defects, are more likely to have higher rates of healthcare utilisation and higher costs (Boulet et al., 2008; Dawson et al., 2014; Frid et al., 2002; 
Accepted manuscript of article accepted for publication in British Journal of Learning Disabilities.

Geelhoed et al., 2011; Schieve et al., 2009). In the USA, greater out-of-pocket medical expenses are incurred by parents of children with Down syndrome, compared to parents of children without Down syndrome (Kageleiry et al., 2017). Again, costs were found to be highest in early childhood.

Due to the increased risk of health problems and increased healthcare costs, it is important to monitor the health and development of children with Down syndrome to identify and treat issues as early as possible. Health monitoring guidelines have been produced for children with Down syndrome, which aim to ensure that (a) unknown health issues are identified and (b) known health issues are monitored at regular and appropriate intervals. In the UK, the Down Syndrome Medical Interest Group (DSMIG, 2011) have published guidelines in a format suitable as inserts for the Personal Child Health Record (PCHR or 'red book'), which is a health and development record given to all parents at a child's birth, and DSMIG also provide further resources and guidance online. Similarly, the American Academy of Paediatrics have produced guidance for clinicians, which lists recommended health checks at different points in development (Baum et al., 2008; Bull \& The Committee on Genetics, 2011; Charleton, Dennis, \& Marder, 2010; Van Cleve \& Cohen, 2006).

Reviews of patient records have generally shown low adherence to monitoring guidelines for Down syndrome. In the USA, Santoro, Martin, Pleatman, and Hopkin (2016) found that only $13 \%$ of children received health monitoring in line with all guidelines; similarly Skotko, Davidson, and Weintraub (2013) reported adherence of 10\%. Inconsistency exists between the guidance for different health conditions, for example in a study with adults with Down syndrome in the USA, greater adherence (50-80\%) was observed for cardiac, reproductive health, dental checks, behavioural and psychological problems, but less than $50 \%$ adherence was observed for sleep apnea, atlanto-axial instability, and hearing and vision problems (Jensen \& Bulova, 2014). Lower adherence rates have been found for the most recent, and potentially less well known guidelines, as well as those that were more invasive, such as those requiring blood tests or sleep studies (Santoro, Martin, Pleatman, et al., 2016). In the UK, Varadkar, Bineham, and Lessing (2003) used a postal questionnaire to survey paediatricians about thyroid screening for children with Down syndrome, and found that $93 \%$ of paediatricians reported that they were screening regularly.

There is inconsistency in the implementation of health monitoring guidelines and the health needs of children with Down syndrome may not always be identified or treated in a timely manner 
Accepted manuscript of article accepted for publication in British Journal of Learning Disabilities.

(McCabe, Hickey, \& McCabe, 2011; McGrath et al., 2011; Santoro, Martin, Pleatman, et al., 2016; Virji-Babul, Eichmann, Kisly, Down, \& Haslam, 2007). The majority of studies exploring adherence to health monitoring guidelines for Down syndrome have been conducted in the USA and have typically included a wide age range of people with Down syndrome. Due to the notable differences in health services delivery between the UK and USA, it is necessary to establish whether guidelines are being adhered to in routine NHS practice in the UK. In addition, there has been little research focussing on health monitoring in early childhood when it is critical that health problems are identified and addressed in order to ensure the best start to life and facilitate long-term health. Currently, research in this area is extremely limited and in need of further development (Henderson, Lynch, Wilkinson, \& Hunter, 2007; van den Driessen Mareeuw, Hollegien, Coppus, Delnoij, \& de Vries, 2017).

\section{Research Questions}

The aim of this study was to investigate whether children with Down syndrome had received recommended health checks at birth and during early childhood, and if known health conditions were monitored. The research questions were:

1. Do health checks occur according to guidelines for young children with Down syndrome?

2. Are children with Down syndrome under the care of the relevant services for their known health conditions?

Parents' perspectives on health monitoring were sought through a questionnaire. By collecting information about children's existing health conditions, recent healthcare usage and whether DSMIG-recommended checks had been conducted, we aimed to examine both screening for unknown health conditions and monitoring of identified health conditions. It was intended that this study would gather preliminary evidence about local health monitoring for children with Down syndrome to facilitate national research in the UK.

\section{Methods}

\section{Design}

This was a descriptive study that used a questionnaire with a cross-sectional sample of parents with children with Down syndrome.

\section{Participants and procedure}

Two groups for families of children with Down syndrome agreed to facilitate recruitment for this study: one parent support group in Central London and one preschool education group in North 
Accepted manuscript of article accepted for publication in British Journal of Learning Disabilities.

London. With permission from managers, a researcher explained the study to parents at group sessions and invited those parents with children with Down syndrome aged 0-5 years to take part in the study.

Those parents who indicated that they wished to take part were provided with paper copies of the information sheet, consent form, questionnaire (see below) and pre-paid addressed envelope. Parents chose whether to complete the questionnaire at the session and return to the researcher, or whether to complete the questionnaire at home and return it via post.

Twenty-four parents took part and their children ranged in age from 10 months to 65 months, with a mean of 32 months (standard deviation - 15 months). Eleven children were female and 13 were male.

The study complied with the British Psychological Society (BPS) Code of Ethics and ethical approval was received from the University of Hertfordshire Health, Sciences, Engineering and Technology Committee.

\section{Measures}

Parents were asked to complete a bespoke questionnaire, with varying response options including multiple-choice and free-text. The questionnaire was designed to capture data about:

- Demographics of the child and parent/carer

- Health problems that the child with Down syndrome experienced

- Number of visits with different healthcare professionals over the previous 12 months

- Health monitoring at birth and since birth

Demographic questions included the child's date of birth and gender. Parents were presented with a list of 17 health conditions and were asked to indicate if their child had any of them. Health conditions were presented alphabetically and included conditions such as cardiac problems, epilepsy, hearing loss and sleep apnea (full list can be seen in Table 1). The list of health conditions was devised drawing on published literature and guidance regarding common health and development issues in Down syndrome (Bull \& The Committee on Genetics, 2011; DSMIG, n.d.-a; Määttä et al., 2011; Skotko et al., 2013; Thomas et al., 2011). A list of 16 health professionals and services was developed based on the list of health problems and previous studies (Thomas et al., 2011). The list included accident and emergency departments, cardiologists, GPs, and neurologists 
Accepted manuscript of article accepted for publication in British Journal of Learning Disabilities.

(full list can be seen in Table 2). Parents were asked to indicate how often they had visited the health professional/service in the previous 12 months for their child with Down syndrome.

The health monitoring questions asked whether children had received health checks at birth (i.e. up to 6 weeks old) and since birth. For checks since birth, the questions also asked parents to note who conducted the check and when the most recent check was conducted. Based on the DSMIG schedule of checks provided in the PCHR, the questionnaire asked about blood checks, breathing checks (since birth only), eye checks, hearing checks, heart checks, measurement of head circumference, measurement of length/height, measurement of weight, thyroid blood tests.

\section{Data analysis}

SPSS 22 was used to analyse the questionnaire data. Data were charted in order to explore health problems experienced by children with Down syndrome, along with the health service provision and health monitoring they had received.

The DSMIG schedule of health check sets out the checks that all children with Down syndrome should receive at birth (Table 3), therefore adherence could be reported. For health checks since birth, guidelines are more nuanced and depend on whether a child is symptomatic therefore any results regarding adherence are preliminary and require further exploration (Table 4).

Following all DSMIG health checks would demonstrate thorough screening for undiagnosed health conditions. Clinical guidelines also highlight that existing conditions should be carefully monitored, therefore it would be expected that children with a diagnosed health condition would have received the relevant health check and be under the care of an appropriate professional. Corresponding conditions, visits to health professionals and occurrence of health checks were identified and charted, with the aim of understanding whether known health conditions were being monitored

\section{Results}

Health conditions in Down syndrome 
Accepted manuscript of article accepted for publication in British Journal of Learning Disabilities.

Parents were asked to indicate whether their child experienced health conditions, from a list of 17 common health and development issues in Down syndrome (where available, prevalence reported by DSMIG (n.d.-b) is noted in the table). As can be seen from Table 1, the most common health condition was hearing loss, which was experienced by $50 \%$ of the children. Cardiac problems, sleep apnea, vision problems and hypothyroidism were each experienced by at least a quarter of the children.

*Please insert Table 1 here*

\section{Health service provision}

Parents were also asked to record how many times they had had contact with different health services over the previous 12 months. Table 2 reports the number of children using each service, and the median number of visits amongst service users. Professionals who were commonly visited included paediatricians, ophthalmologists, audiologists, physiotherapists, speech and language therapists and GPs. Few children saw an occupational therapist, neurologist or psychiatrist, but those who did, saw them a relatively high number of times. No children had seen a dermatologist in the previous 12 months.

*Please insert Table 2 here*

There were missing data for GP visits, as some parents stated that there had been "many" visits but did not give a number. Other parents also reported that they had had additional phone or email contact with their GP, therefore the number of contacts with GP is likely to be higher than the median of four visits.

\section{Health checks at birth}

Parents were asked to indicate which of the checks shown in Table 3 were carried out at birth, or soon after (i.e. within 6 weeks). Table 3 also shows the DSMIG (2011) health monitoring recommendation for these checks. Ten children (42\%) had received all health checks at birth, and nine children (38\%) had not. Five parents had indicated that they did not know for at least one of the health checks. Considering the checks individually, most of the checks were carried out on all, or the majority of children. A small number of parents stated that they could not remember whether some of the checks were conducted. 
Accepted manuscript of article accepted for publication in British Journal of Learning Disabilities.

In summary, although most of the health checks were carried out on the majority of children, $38 \%$ of children had not received all the recommended health checks at birth.

*Please insert Table 3 here*

\section{Health checks since birth}

The results regarding health checks since birth were more variable, as shown in Table 4 . The majority of children had received eye, hearing, length/height, weight and thyroid checks. The response for blood checks was particularly low, at $38 \%$. As shown in Table 4, it is not necessarily the case that all children should have received all health checks according to the DSMIG guidelines.

*Please insert Table 4 here*

The majority of parents were able to indicate whether or not health checks had taken place since birth. However, some parents omitted the questions about when the last check was and who had conducted the check. Therefore, the results regarding these questions should be considered preliminary. The median length of time since the most recent check ranged from 5 to 9 months for the different checks, although there was a substantial degree of variation, with some parents reporting checks over two years previously (Table 5). Parents reported that paediatricians conducted many of the checks. For eye, hearing and heart checks, the relevant specialist was the most common answer e.g. ophthalmologist, audiologist and cardiologist. Health visitors were reported to conduct some of the measurement checks, i.e. health circumference, length/height and weight.

*Please insert Table 5 here*

As highlighted in the monitoring guidelines, it is important that children presenting with health issues receive the appropriate checks and healthcare provision. The conditions most closely aligned with a health check were selected - sleep apnea (breathing check), cardiac problems (heart check), weigh problems (measurement of weight and height/length), vision problems (eye check), hearing loss (hearing check), otitis media (hearing check) and hypothyroidism (thyroid check). Table 5 shows the number of children with these health conditions who had received the relevant health check since birth and saw a relevant healthcare professional. From this data, the majority of identified health conditions appear to be monitored by healthcare professionals. The exception to this may be sleep apnea as only $63 \%$ of children with this condition had received a breathing check since birth.

In summary, ongoing health check rates were lower compared to health checks at birth. In order to understand this in more detail, it is important to distinguish between monitoring of known 
Accepted manuscript of article accepted for publication in British Journal of Learning Disabilities.

conditions and screening for unknown conditions. For the majority of known conditions, children had received the relevant health check and saw the appropriate professional although sleep apnea was the notable exception.

*Please insert Table 6 here*

\section{Discussion}

Children with Down syndrome can have complex health needs, however the quality and consistency of health service provision is unclear, including the extent to which health professionals adhere to health monitoring guidelines (van den Driessen Mareeuw et al., 2017). This study aimed to gather parent reports on health service provision and monitoring for children with Down syndrome aged 05 years in the UK.

In line with previous research, the children with Down syndrome in this study experienced a range of health conditions, most commonly hearing loss, cardiac problems, sleep apnea, vision problems and hypothyroidism. Families of children with Down syndrome reported high usage of healthcare services, with the majority of children having seen an audiologist, paediatrician, ophthalmologist, physiotherapist, speech and language therapist and GP in the previous 12 months. The professionals who were visited most frequently tended to be those who provided a therapy, for example physiotherapists, speech and language therapists and occupational therapists.

The adherence to DSMIG health monitoring guidelines at birth was high for most of the health checks, although $38 \%$ of parents reported that their child had not received all of the recommended health checks at birth. Some of the checks recommended for newborns with Down syndrome are part of national guidelines for all newborns in England e.g. hearing check, which may contribute to the high adherence rates. Since birth, blood checks, breathing checks and measurement of head circumference were least likely to be conducted, as reported by parents. With the exception of children with sleep apnea, the majority of children who had a diagnosed health condition received the relevant health check and were under the care of the relevant health professional. This raises the possibility that screening for undiagnosed health conditions may not be consistently taking place, contributing to the difference between health checks received and those which are recommended. Early intervention for children with Down syndrome is considered crucial by parents and care providers (Marshall, Tanner, Kozyr, \& Kirby, 2015); if screening does not occur, then health 
Accepted manuscript of article accepted for publication in British Journal of Learning Disabilities.

conditions may be diagnosed later or not at all, leading to a delay in appropriate treatment for children with Down syndrome, and poorer long-term outcomes.

Sleep apnea is highly prevalent in children with Down syndrome (Lee, Lee, Hsueh, Lin, \& Kang, 2018), and can have significant implications for health and development so it is crucial that once diagnosed, it is managed appropriately (Simpson, Oyekan, Ehsan, \& Ingram, 2018). In the present study, parents were asked if their child had received a breathing check and $63 \%$ of the children with sleep apnea had received such a check in the previous 12 months. Although physical examination and histories are important, it is recommended that children with, or suspected of having, sleep apnea should have further investigations, for example polysomnography (PSG) (Alsubie \& Rosen, 2018; Kaditis et al., 2016). It may be that children in the present study with sleep apnea were receiving monitoring of their condition through other means, e.g. PSG, rather than breathing checks. However, this potential explanation warrants further investigation, as findings from the USA suggest that children with Down syndrome who were symptomatic of sleep apnea were not more likely to receive PSG than children who were not symptomatic of sleep apnea (Santoro, Yin, \& Hopkin, 2017).

Previous studies in the USA have shown that there is variability in the adherence to the different health checks. Generally the adherence rate in American studies are lower than those presented in this study, for example the high adherence to thyroid checks in this study is consistent with previous research in the UK (Varadkar et al., 2003), but this pattern is not consistent with research in the USA (Santoro, Martin, Pleatman, et al., 2016; Santoro et al., 2017; Skotko et al., 2013). This may be due to differences in the health care systems, study methodologies or characteristics of the families who took part.

\section{Limitations}

This is a preliminary study in an area of limited research, designed to gain new insights into the health monitoring of children with Down syndrome in the UK. However, there are limitations with this study. It was carried out with a small sample of parents in Greater London recruited from education and support groups. This group may be more proactively involved in their child's care, and the findings may not be representative of services across the UK or other families of children with Down syndrome. 
Accepted manuscript of article accepted for publication in British Journal of Learning Disabilities.

Parent report was used to measure adherence to health monitoring guidelines. It is important to seek parents' perspectives on health care, and many parents become experts in their child's health conditions and healthcare. However parents may have difficulty remembering specific appointments and there can be discrepancies between parental perceptions of adherence and adherence in practice (Santoro, Martin, \& Hopkin, 2016). In the present study, the majority of parents were able to indicate if checks at birth and since birth had occurred or not, but there were higher levels of missing data for some questions about when checks since birth were conducted and who by. An analysis of patient records and surveying clinicians in the UK would provide valuable additional evidence about health monitoring for children with Down syndrome.

\section{Implications}

Close monitoring of potential health issues in the early years is key to minimising health inequalities, and ensuring that children with Down syndrome receive the best start to life and have positive health outcomes (Cohen, 1999; Marshall et al., 2015; Van Allen, Fung, \& Jurenka, 1999). It is important to benchmark current practice and identify potential issues so that clinical practice can be improved for people with Down syndrome (Henderson et al., 2007). Adherence to health monitoring guidelines could act as a quality indicator of healthcare for individuals with Down syndrome, leading to insights about the standard of healthcare and clinical outcomes thereby informing evidencebased change to clinical practice (van den Driessen Mareeuw et al., 2017).

This study suggests that there is variable health monitoring after birth in the UK, and that this may particularly affect screening for undiagnosed conditions. The introduction of specialised services and educational interventions for paediatricians in the USA have been found to improve adherence to guidelines and result in additional and more accurate diagnoses of health conditions, which can then be treated (Santoro, Martin, Pleatman, et al., 2016; Skotko et al., 2013). The intervention in Santoro et al. (2016) consisted of providing paediatricians with a simple checklist for health monitoring for children with Down syndrome that they could consult during an appointment. Similar initiatives may also improve screening, and therefore quality of care, in the UK. Additional training and education for clinicians should aim to increase awareness and adherence to Down syndrome guidelines (Määttä et al., 2011; Mengoni \& Redman, 2019).

\section{Conclusions}


Accepted manuscript of article accepted for publication in British Journal of Learning Disabilities.

Young children with Down syndrome have an increased likelihood of experiencing potentially serious health conditions. Health monitoring guidelines promote and facilitate the identification and treatment of health issues, therefore it is important that they are adhered to. There is limited research regarding if and how these guidelines are used in the UK. This study provides evidence that although health monitoring at birth largely follows the published guidelines, health monitoring after birth may be more variable. This study suggests that diagnosed health conditions are monitored for most children during early childhood, but the rates of screening for unknown health conditions are lower. There is the potential for significant health issues to be missed through variable screening and therefore not addressed, increasing health inequalities. Although further research is needed to explore this, and to corroborate these findings, this suggests that health monitoring guidelines may need to be further embedded in UK clinical practice for children with Down syndrome. 
Accepted manuscript of article accepted for publication in British Journal of Learning Disabilities.

\section{References}

Allerton, L. A., Welch, V., \& Emerson, E. (2011). Health inequalities experienced by children and young people with intellectual disabilities:A review of literature from the United Kingdom. Journal of Intellectual Disabilities, 15(4), 269-278. doi:10.1177/1744629511430772

Alsubie, H. S., \& Rosen, D. (2018). The evaluation and management of respiratory disease in children with Down syndrome (DS). Paediatric Respiratory Reviews, 26, 49-54. doi:10.1016/j.prrv.2017.07.003

Baum, R. A., Nash, P. L., Foster, J. E. A., Spader, M., Ratliff-Schaub, K., \& Coury, D. L. (2008). Primary Care of Children and Adolescents with Down Syndrome: An Update. Current Problems in Pediatric and Adolescent Health Care, 38(8), 241-261. doi:10.1016/j.cppeds.2008.07.001

Boulet, S. L., Molinari, N.-A., Grosse, S. D., Honein, M. A., \& Correa-Villaseñor, A. (2008). Health Care Expenditures for Infants and Young Children with Down Syndrome in a Privately Insured Population. The Journal of Pediatrics, 153(2), 241-246. doi:10.1016/j.jpeds.2008.02.046

Bull, M. J., \& The Committee on Genetics. (2011). Clinical Report-Health Supervision for Children With Down Syndrome. Pediatrics, 128(2), 393-406. doi:10.1542/peds.2011-1605

Charleton, P. M., Dennis, J., \& Marder, E. (2010). Medical management of children with Down syndrome. Paediatrics and Child Health, 20(7), 331-337. doi:10.1016/j.paed.2010.06.006

Cleves, M. A., Hobbs, C. A., Cleves, P. A., Tilford, J. M., Bird, T. M., \& Robbins, J. M. (2007). Congenital defects among liveborn infants with Down syndrome. Birth Defects Research Part A: Clinical and Molecular Teratology, 79(9), 657-663. doi:10.1002/bdra.20393

Cohen, W. I. (1999). Health care guidelines for individuals with Down Syndrome-1999 revision. Down syndrome Quarterly, 4(3), 1-16.

Dawson, A. L., Cassell, C. H., Oster, M. E., Olney, R. S., Tanner, J. P., Kirby, R. S., . . Grosse, S. D. (2014). Hospitalizations and associated costs in a population-based study of children with Down Syndrome born in Florida. Birth Defects Research Part A: Clinical and Molecular Teratology, 100(11), 826-836. doi:10.1002/bdra.23295

DSMIG. (2011). PCHR insert. In. Retrieved from www.dsmig.org.uk/publications/pchr.html

DSMIG. (n.d.-a). Guidelines for Essential Medical Surveillance. Retrieved from http://www.dsmig.org.uk/publications/guidelines.html

DSMIG. (n.d.-b). Information and resources. Retrieved from https://www.dsmig.org.uk/informationresources/

Frid, C., Annerén, G., Rasmussen, F., Sundelin, C., \& Drott, P. (2002). Utilization of medical care among children with Down's syndrome. Journal of Intellectual Disability Research, 46(4), 310-317. doi:10.1046/j.1365-2788.2002.00392.x

Geelhoed, E. A., Bebbington, A., Bower, C., Deshpande, A., \& Leonard, H. (2011). Direct health care costs of children and adolescents with Down syndrome. Journal of Pediatrics, 159(4), 541545. doi:10.1016/j.jpeds.2011.06.007

Henderson, A., Lynch, S. A., Wilkinson, S., \& Hunter, M. (2007). Adults with Down's syndrome: the prevalence of complications and health care in the community. British Journal of General Practice, 57(534), 50-55.

Jensen, K. M., \& Bulova, P. D. (2014). Managing the care of adults with Down's syndrome. BMJ, 349, g5596. doi:10.1136/bmj.g5596

Kaditis, A. G., Alonso Alvarez, M. L., Boudewyns, A., Alexopoulos, E. I., Ersu, R., Joosten, K., .. Verhulst, S. (2016). Obstructive sleep disordered breathing in 2- to 18-year-old children: diagnosis and management. European Respiratory Journal, 47(1), 69-94. doi:10.1183/13993003.00385-2015

Kageleiry, A., Samuelson, D., Duh, M. S., Lefebvre, P., Campbell, J., \& Skotko, B. G. (2017). Out-ofpocket medical costs and third-party healthcare costs for children with Down syndrome. American Journal of Medical Genetics Part A, 173(3), 627-637. doi:10.1002/ajmg.a.38050 
Accepted manuscript of article accepted for publication in British Journal of Learning Disabilities.

Lee, C.-F., Lee, C.-H., Hsueh, W.-Y., Lin, M.-T., \& Kang, K.-T. (2018). Prevalence of Obstructive Sleep Apnea in Children With Down Syndrome: A Meta-Analysis. Journal of Clinical Sleep Medicine, 14(05), 867-875. doi:10.5664/jcsm.7126

Määttä, T., Määttä, J., Tervo-Määttä, T., Taanila, A., Kaski, M., \& livanainen, M. (2011). Healthcare and guidelines: A population-based survey of recorded medical problems and health surveillance for people with Down syndrome. Journal of Intellectual \& Developmental Disability, 36(2), 118-126. doi:10.1080/13668250.2011.570253

Marshall, J., Tanner, J. P., Kozyr, Y. A., \& Kirby, R. S. (2015). Services and supports for young children with Down syndrome: parent and provider perspectives. Child: Care, Health \& Development, 41(3), 365-373. doi:10.1111/cch.12162

McCabe, L. L., Hickey, F., \& McCabe, E. R. B. (2011). Down Syndrome: Addressing the Gaps. The Journal of Pediatrics, 159(4), 525-526. doi:10.1016/j.jpeds.2011.06.026

McGrath, R. J., Stransky, M. L., Cooley, W. C., \& Moeschler, J. B. (2011). National Profile of Children with Down Syndrome: Disease Burden, Access to Care, and Family Impact. The Journal of Pediatrics, 159(4), 535-540.e532. doi:10.1016/j.jpeds.2011.04.019

Mengoni, S. E., \& Redman, S. (2019). Evaluating Health Visitors' Existing Knowledge of Down Syndrome and the Effect of a Training Workshop. Journal of Policy and Practice in Intellectual Disabilities, 16(1), 30-36. doi:10.1111/jppi.12271

Santoro, S. L., Martin, L. J., \& Hopkin, R. J. (2016). Screening for Hematological Disorders in Mosaic Down Syndrome:Parent Report of Experiences. Clinical Pediatrics, 55(5), 421-427. doi:10.1177/0009922815589911

Santoro, S. L., Martin, L. J., Pleatman, S. I., \& Hopkin, R. J. (2016). Stakeholder buy-in and physician education improve adherence to guidelines for Down syndrome. The Journal of Pediatrics, 171, 262-268. e262. doi:10.1016/j.jpeds.2015.12.026

Santoro, S. L., Yin, H., \& Hopkin, R. J. (2017). Adherence to Symptom-Based Care Guidelines for Down Syndrome. Clinical Pediatrics, 56(2), 150-156. doi:doi:10.1177/0009922816652416

Schieve, L. A., Boulet, S. L., Boyle, C., Rasmussen, S. A., \& Schendel, D. (2009). Health of children 3 to 17 years of age with Down syndrome in the 1997-2005 National Health Interview Survey. Pediatrics, 123(2), e253-e260. doi:10.1542/peds.2008-1440

Simpson, R., Oyekan, A. A., Ehsan, Z., \& Ingram, D. G. (2018). Obstructive sleep apnea in patients with Down syndrome: current perspectives. Nature and science of sleep, 10, 287. doi:10.2147/NSS.S154723

Skotko, B. G., Davidson, E. J., \& Weintraub, G. S. (2013). Contributions of a specialty clinic for children and adolescents with Down syndrome. American Journal of Medical Genetics Part A, 161(3), 430-437. doi:10.1002/ajmg.a.35795

Thomas, K., Bourke, J., Girdler, S., Bebbington, A., Jacoby, P., \& Leonard, H. (2011). Variation Over Time in Medical Conditions and Health Service Utilization of Children with Down Syndrome. The Journal of Pediatrics, 158(2), 194-200.e191. doi:10.1016/j.jpeds.2010.08.045

Van Allen, M. I., Fung, J., \& Jurenka, S. B. (1999). Health care concerns and guidelines for adults with Down syndrome. American Journal of Medical Genetics Part A, 89(2), 100-110.

Van Cleve, S. N., \& Cohen, W. I. (2006). Part I: Clinical Practice Guidelines for Children With Down Syndrome From Birth to 12 Years. Journal of Pediatric Health Care, 20(1), 47-54. doi:10.1016/j.pedhc.2005.10.004

van den Driessen Mareeuw, F. A., Hollegien, M. I., Coppus, A. M., Delnoij, D. M., \& de Vries, E. (2017). In search of quality indicators for Down syndrome healthcare: a scoping review. BMC Health Services Research, 17(1), 284. doi:10.1186/s12913-017-2228-x

Varadkar, S., Bineham, G., \& Lessing, D. (2003). Thyroid screening in Down's syndrome: current patterns in the UK. Archives of disease in childhood, 88(7), 647-647.

Virji-Babul, N., Eichmann, A., Kisly, D., Down, J., \& Haslam, R. H. (2007). Use of health care guidelines in patients with Down syndrome by family physicians across Canada. Paediatrics \& Child Health, 12(3), 179-183. 
Accepted manuscript of article accepted for publication in British Journal of Learning Disabilities.

Wu, J., \& Morris, J. K. (2013). Trends in maternal age distribution and the live birth prevalence of Down/'s syndrome in England and Wales: 1938-2010. European Journal of Human Genetics, 21(9), 943-947. doi:10.1038/ejhg.2012.288 
Accepted manuscript of article accepted for publication in British Journal of Learning Disabilities.

Table 1 - Health conditions experienced by the children with Down syndrome

\begin{tabular}{|c|c|c|}
\hline Condition & Number (\%) of children & DSMIG prevalence \\
\hline Hearing loss & $12(50 \%)$ & $50-70 \%$ \\
\hline Cardiac problems & $9(38 \%)$ & $40-60 \%$ \\
\hline Sleep apnea & $8(33 \%)$ & $30-77 \%$ \\
\hline Vision problems & $7(29 \%)$ & $50 \%$ \\
\hline Hypothyroidism & $6(25 \%)$ & $10 \%$ \\
\hline Otitis media & $4(17 \%)$ & $\begin{array}{l}93 \% \text { at } 1 \text { year, } 68 \% \text { at } 5 \\
\text { years }\end{array}$ \\
\hline Skin conditions & $3(13 \%)$ & $\mathrm{n} / \mathrm{a}$ \\
\hline Weight issues & $3(13 \%)$ & $\mathrm{n} / \mathrm{a}$ \\
\hline Behavioural problems & $2(8 \%)$ & $\mathrm{n} / \mathrm{a}$ \\
\hline Autism spectrum disorder & $1(4 \%)$ & $10 \%$ \\
\hline Epilepsy & $1(4 \%)$ & $\mathrm{n} / \mathrm{a}$ \\
\hline Asthma & 0 & $\mathrm{n} / \mathrm{a}$ \\
\hline Atlantoaxial instability & 0 & $1-2 \%$ \\
\hline Coeliac disease & 0 & $1-19 \%$ \\
\hline Hyperthyroidism & 0 & $\mathrm{n} / \mathrm{a}$ \\
\hline Leukaemia & 0 & $1-2 \%$ \\
\hline Psychiatric problems & 0 & $18-38 \%$ \\
\hline
\end{tabular}


Accepted manuscript of article accepted for publication in British Journal of Learning Disabilities.

Table 2 - Health service use over the previous 12 months

\begin{tabular}{|c|c|c|}
\hline Health service/professional & $\begin{array}{l}\mathbf{N}(\%) \text { of children } \\
\text { using this service }\end{array}$ & Median number of visits (range) \\
\hline Audiologist & $24(100 \%)$ & $2(1-6)$ \\
\hline Paediatrician & $22(92 \%)$ & $1.5(1-5)$ \\
\hline Ophthalmologist & $22(92 \%)$ & $2(1-3)$ \\
\hline Speech and language therapist ${ }^{a}$ & $21(88 \%)$ & $6(1-70)$ \\
\hline Physiotherapist & $20(83 \%)$ & $3(1-16)$ \\
\hline$G P^{b}$ & $17(71 \%)$ & $4(1-12)$ \\
\hline Accident and emergency & $15(63 \%)$ & $1(1-8)$ \\
\hline Dentist & $14(58 \%)$ & $2(1-2)$ \\
\hline Cardiologist & $13(54 \%)$ & $1(1-2)$ \\
\hline Health visitor & $11(46 \%)$ & $2(1-12)$ \\
\hline Nurse & $5(17 \%)$ & $2(1-4)$ \\
\hline Occupational therapist & $5(17 \%)$ & $4(2-6)$ \\
\hline Midwife & $2(8 \%)$ & $5(4-6)$ \\
\hline Psychiatrist & $1(4 \%)$ & $5(5-5)$ \\
\hline Neurologist & $1(4 \%)$ & $1(1-1)$ \\
\hline Dermatologist & 0 & $\mathrm{n} / \mathrm{a}$ \\
\hline
\end{tabular}

${ }^{\mathrm{a}} \mathrm{N}=21$

${ }^{b} \mathrm{~N}=20$ 
Table 3 - Health checks at birth (0-6 weeks)

\begin{tabular}{|c|c|c|c|c|}
\hline & \multicolumn{3}{|c|}{ Number of children (\%) } & \multirow[t]{2}{*}{ DSMIG health monitoring recommendations at birth } \\
\hline & $\begin{array}{l}\text { Check was } \\
\text { conducted at } \\
\text { birth }\end{array}$ & $\begin{array}{l}\text { Check was not } \\
\text { conducted at birth }\end{array}$ & $\begin{array}{l}\text { Did not know if check } \\
\text { was conducted at birth }\end{array}$ & \\
\hline Blood & $18(75 \%)$ & $3(13 \%)$ & $3(13 \%)$ & Newborn blood test \\
\hline Eye & $14(57 \%)$ & $7(29 \%)$ & $3(13 \%)$ & Newborn routine eye check \\
\hline Hearing & $24(100 \%)$ & 0 & 0 & Newborn universal hearing screen \\
\hline Heart & $23(96 \%)$ & $1(4 \%)$ & 0 & Assessment (including echocardiogram) by 6 weeks \\
\hline $\begin{array}{l}\text { Head circumference } \\
\text { a }\end{array}$ & $21(88 \%)$ & $1(4 \%)$ & $1(4 \%)$ & $\begin{array}{l}\text { Checked and charted against Down syndrome growth } \\
\text { charts }\end{array}$ \\
\hline Length & $21(88 \%)$ & $1(4 \%)$ & $2(8 \%)$ & $\begin{array}{l}\text { Checked and charted against Down syndrome growth } \\
\text { charts }\end{array}$ \\
\hline Weight & $24(100 \%)$ & 0 & 0 & $\begin{array}{l}\text { Checked and charted against Down syndrome growth } \\
\text { charts }\end{array}$ \\
\hline Thyroid & $22(92 \%)$ & $1(4 \%)$ & $1(4 \%)$ & Newborn routine heel prick test \\
\hline
\end{tabular}

${ }^{a} \mathrm{~N}=23$ 
Table 4 - Health checks since birth (6 weeks onwards)

\begin{tabular}{|c|c|c|c|c|}
\hline & \multicolumn{3}{|l|}{$\mathrm{N}$ of children (\%) } & \multirow{2}{*}{$\begin{array}{l}\text { DSMIG preschool health monitoring } \\
\text { recommendations }\end{array}$} \\
\hline & $\begin{array}{l}\text { Check was } \\
\text { conducted since } \\
\text { birth }\end{array}$ & $\begin{array}{l}\text { Check was not } \\
\text { conducted since } \\
\text { birth }\end{array}$ & $\begin{array}{l}\text { Did not know if check } \\
\text { was conducted since } \\
\text { birth }\end{array}$ & \\
\hline Blood $^{\text {a }}$ & $9(38 \%)$ & $10(42 \%)$ & $4(17 \%)$ & $\begin{array}{l}\text { If blood film at birth is abnormal, follow-up } \\
\text { checks may be needed }\end{array}$ \\
\hline Breathing $^{a}$ & $14(58 \%)$ & $8(33 \%)$ & $1(4 \%)$ & $\begin{array}{l}\text { Enquire about uneven breathing during sleep } \\
\text { and poor quality sleep at every review. Low } \\
\text { threshold for sleep studies }\end{array}$ \\
\hline Eye & $23(96 \%)$ & $1(4 \%)$ & 0 & $\begin{array}{l}\text { Eye and vision examination at } 18-24 \text { months, } \\
\text { and at } 4 \text {-years. Visual behaviour to be } \\
\text { monitored at every review }\end{array}$ \\
\hline Hearing & $24(100 \%)$ & 0 & $1(4 \%)$ & $\begin{array}{l}\text { Hearing assessment at 6-10 months and then } \\
\text { annually }\end{array}$ \\
\hline Heart $^{b}$ & $16(67 \%)$ & $5(21 \%)$ & 0 & Low threshold for reviewing heart status \\
\hline
\end{tabular}


Accepted manuscript of article accepted for publication in British Journal of Learning Disabilities.

\begin{tabular}{|c|c|c|c|c|}
\hline Head circumference $^{b}$ & $14(58 \%)$ & $7(29 \%)$ & $1(4 \%)$ & Measurements made as clinically indicated \\
\hline Length/height ${ }^{a}$ & $22(92 \%)$ & $1(4 \%)$ & 0 & $\begin{array}{l}\text { Checked and charted frequently until } 2 \text { years } \\
\text { old, then checked and charted at least } \\
\text { annually }\end{array}$ \\
\hline Weight $^{c}$ & $22(92 \%)$ & 0 & 0 & $\begin{array}{l}\text { Checked and charted frequently until } 2 \text { years } \\
\text { old, then checked and charted at least } \\
\text { annually }\end{array}$ \\
\hline Thyroid $^{\text {a }}$ & $23(96 \%)$ & 0 & 0 & $\begin{array}{l}\text { Annual fingerprick thyroid-stimulating } \\
\text { hormone test or } 2 \text { yearly thyroid blood tests }\end{array}$ \\
\hline
\end{tabular}


Accepted manuscript of article accepted for publication in British Journal of Learning Disabilities.

Table 5 - Median length of time since last health check

\begin{tabular}{|c|c|c|}
\hline & $\begin{array}{l}\text { Median length of time in months } \\
\text { since last check (range) }\end{array}$ & Number of respondents \\
\hline Blood & $6(2-15)$ & 7 \\
\hline Breathing & $4(1-9)$ & 7 \\
\hline Eye & $4(0-12)$ & 19 \\
\hline Hearing & $3(1-14)$ & 20 \\
\hline Heart & $6(3-30)$ & 13 \\
\hline Head circumference & $9(1-24)$ & 7 \\
\hline Length/height & $3(0-24)$ & 17 \\
\hline Weight & $3(0-24)$ & 17 \\
\hline Thyroid & $5(1-15)$ & 16 \\
\hline
\end{tabular}


Accepted manuscript of article accepted for publication in British Journal of Learning Disabilities.

Table 6 - Monitoring of known health issues

\begin{tabular}{|l|l|l|}
\hline Condition & $\begin{array}{l}\text { Relevant check since birth and N of children } \\
\text { affected (\%) who received this check }\end{array}$ & $\begin{array}{l}\text { Relevant health professional } \\
\text { and N of children affected (\%) } \\
\text { who had seen them within 12 } \\
\text { months }\end{array}$ \\
\hline Sleep apnea & Breathing check - 5 (63\%) & Paediatrician - 8 (100\%) \\
\hline Vision problems & Eye check - 7 (100\%) & Ophthalmologist - 7 (100\%) \\
\hline Hearing loss & Hearing check - 12 (100\%) & Audiologist - 12 (100\%) \\
\hline Otitis media & Hearing check - 4 (100\%) & Audiologist - 4 (100\%) \\
\hline Cardiac problems & Heart check - 8 (89\%) & Pardiologist - 9 (100\%) \\
\hline Weight issues & Measurement of weight - 3 (100\%) & Paediatrician - 6 (100\%) \\
\hline Hypothyroidism & Measurement of length/height - 3 (100\%) & \\
\hline
\end{tabular}

